\title{
Electrospray ionization mass spectrometry as a valuable tool in the characterization of novel primaquine peptidomimetic derivatives
}

\author{
Nuno Vale, ${ }^{a}$ Joana Matos, ${ }^{a}$ Rui Moreira ${ }^{\mathrm{b}}$ and Paula Gomes ${ }^{\mathrm{a},{ }^{*}}$ \\ ${ }^{a}$ Centro de Investigação em Química da Universidade do Porto, Departamento de Química, Faculdade de Ciências, Universidade do Porto, \\ R. Campo Alegre 687,.P-4169-007 Porto,Portugal.E-mail:pgomes@fc.up.pt \\ biMed.UL-Centro de Estudos de Ciências Farmacêuticas, Faculdade de Farmácia, Universidade de Lisboa, Lisboa, Portugal
}

\begin{abstract}
Novel primaquine-derived antimalarials have been extensively characterized by electrospray ionization-ion trap mass spectrometry (ESI-MS). Experiments by in-source collision-induced dissociation (CID) in the nozzle-skimmer region (NSR) or by tandem mass spectrometry (MS/MS) are shown to be most valuable tools for the physico-chemical characterization of these 8-aminoquinolinic drugs that also bear the biologically relevant imidazolidin-4-one scaffold. It was possible to find parallelism between compound stability in the NSR and its reactivity towards hydrolysis at physiological pH and T. Moreover, MS/MS fragmentation patterns were characteristic for each family, providing a means for structural distinction of isomers and allowing interesting correlations to be found between the relative abundance of particular fragments and relevant structure-activity determinants, such as the Charton steric parameter, $\nu$. In conclusion, this work provides a solid ground for establishing ESI-MS as a key tool for the physico-chemical characterization of biopharmaceuticals bearing the 8-aminoquinoline and/or the imidazolidin-4-one moieties.
\end{abstract}

Keywords: 8-aminoquinoline, antimalarial, ESI-MSn , fragmentation, imidazolidin-4-one, malaria, peptidomimetic, primaquine

\section{Introduction}

Since the technique was introduced by Yamashita and Fenn in 1984, ${ }^{1}$ electrospray ionization mass spectrometry (ESI-MS) has been increasingly applied to the study of drugs, either from a natural or a synthetic origin. Structural information on drugs has been obtained by cone voltage fragmentation with a single MS instrument, collisionally induced dissociation (CID) with triple quadrupole MS instruments, MS $^{n}$ techniques using quadrupole ion-trap (QIT) instrumentation and time-of-flight mass spectrometry (ToF-MS). ${ }^{2}$ However, these studies are often only targeted at the structural analysis of the drugs, without any further attempts to correlate drug fragmentation patterns with other physico-chemical characteristics of the drugs. Despite drug degradation pathways under the ESI-MS analysis conditions being quite different from those occurring in the condensed state at mild conditions, as in aqueous media at physiological $\mathrm{pH}$ and $T$. the qualitative assessment of eventual parallelisms between both situations is of the utmost importance for drug analysis and stability predictions.

8-Aminoquinolines (8-AQ), currently primaquine and bulaquine, are the only class of drugs approved for treatment of relapsing cases of Plasmodium vivax malaria. Prominent 
action of $8-A Q$ against sexual stages of the malaria parasite also makes them the drugs of choice for malaria-transmissionblocking activity. ${ }^{3}$ Primaquine (1,PQ), however, cannot be used in patients having glucose-6-phosphate dehydrogenase deficiency as it causes hemolytic anemia ${ }^{4}$ and is affected by low oral bioavailability mainly due to its extensive conversion into inactive carboxyprimaquine, by oxidative deamination. ${ }^{5,6}$ Previous research devoted to minimize these problems was based on $P Q$ acylation with amino acids and oligopeptides, which led to some progress in the drug's therapeutic profile..$^{7-13}$ However, amino acids and peptide derivatives of $P Q$ are rapidly hydrolyzed to $P Q$ by aminopeptidases and endopeptidases, ${ }^{10,12}$ suggesting that they might undergo extensive hydrolysis to the parent drug in the $\mathrm{Gl}$ tract when given orally.

Over the last five years, we have been working on peptidestable derivatives of $P Q$ obtained by acylation of its primary amino group with an amino acid to yield $\alpha$-aminoamides such as 2 or 3 , which are then converted into imidazolidin-4-ones such as $\mathbf{4}$ or 5 by reaction with a carbonyl compound. ${ }^{14-17}$ Some of these imidazolidin-4-ones were found to inhibit the development of the sporogonic cycle of Plasmodium berghei malaria as efficiently as the parent drug, ${ }^{15}$ while being highly stable both in human plasma and isotonic buffer. ${ }^{14,15}$ Further, these compounds were recently found to be active against both Pneumocystis carinii and the chloroquine-resistant Plasmodium falciparum W2 strain, in the $\mu \mathrm{M}$ range. ${ }^{18}$

Taking $\mathbf{4}$ and $\mathbf{5}$ as leads, we set out to prepare peptidomimetic derivatives of $P Q$ 6-8, whose structures can be regarded as mimetics of PQXaaPro/PQProXaa $\alpha$-aminoamides such as $3{ }^{19,20}$ Compounds 8 were recently found to be highly stable at physiological $\mathrm{pH}$ and $T$, while being active against the Plasmodium falciparum W2 strain and efficiently inhibiting the development of the sporogonic cycle of Plasmodium berghei. ${ }^{20}$ In turn, compounds $\mathbf{6}$ and $\mathbf{7}$ were found to be potentially useful as $P Q$ prodrugs. ${ }^{19}$

Given the relevance of compounds 4-8 as prospective pharmaceuticals, we have recently developed a methodology for further physico-chemical characterization of the title compounds by means of ESI-MS techniques. ${ }^{21,22}$ Our aim was to get a deeper insight into the structural features of drug-derived structures bearing both the imidazolidin-4-one and the 8-AQ scaffolds, as similar studies are scarce in the literature. Moreover, the most relevant examples of analytical studies focused on $P Q$ and related structures ${ }^{23-41}$ are essentially focused on compound separation/identification, with very few examples where MS fragmentation studies are the core of the reported work. Therefore, the present is a brief report on the comparative study of the aforementioned families of $P Q$-derived imidazolidin-4-ones (4-8) by ESI-MS fragmentation techniques, and on the search for possible correlations between ESI-MS data and other known properties for these compounds. Both the parent drug $(P Q, 1)$ and other $P Q$ imidazolidin-4-ones with additional structural changes, such as acetylation of secondary amino groups $(9,10)$ or modification of the quinoline ring (10) were included in the study for an assessment of their effect on compound's properties.

\section{Experimental Synthesis of the imidazolidin-4-one
derivatives}

The synthesis and spectral characterization of compounds 4-10 have been reported elsewhere. ${ }^{14,20,21,42} P Q$ derivatives $\mathbf{4 g}$ and $5 \mathrm{e}$, as well as imidazolidin-4-one 11, were successfully prepared by similar methods, respectively, from $P Q$ and from 2-tert-butyl-primaquine (BPQ), the latter prepared as previously described in the literature. . $3,44^{-4}$

\section{Instrumentation and analytical conditions}

ESI-MS studies on all compounds were achieved using a Finnigan Surveyor LCQ DECA XP MAX quadrupole ion trap mass spectrometer (San José, CA, USA), utilizing ESI. In the ESI source, nitrogen sheath gas flow was maintained at 20 psi, the capillary temperature was set to $275^{\circ} \mathrm{C}$ and the spray voltage was set to $5 \mathrm{kV}$. Capillary voltage was of $15 \mathrm{~V}$ and the tube lens voltage was of $30 \mathrm{~V}$. The instrument was calibrated with caffeine (Aldrich), MRFA (tetrapeptide, Thermo Finnigan), Ultramark 1621 (Lancaster) in the mass range of 195-1821.

To induce sample fragmentation, two processes were used: in-source collision-induced dissociation (CID) in the nozzleskimmer region and tandem mass spectrometry (MS/MS). For full details see references. ${ }^{21,22}$ Briefly, in the first process, fragmentation is induced by colliding sample ions with the background gas in the intermediate-pressure region of the ESI interface. This region is also called "nozzle-skimmer" and pressure gas is about $10^{-1}$ mbar. Increasing the voltage between the nozzle and the skimmer (Vs CID) increases the kinetic energy of the ions passing through this region. This raises the energy of collision between the ions and background gas, eventually causing fragmentation. ${ }^{45} \mathrm{MS} / \mathrm{MS}$ occurs at the high vacuum region of the mass analyzer; the ion of interest is isolated within the ion trap by ejecting all other ions out of the trap. Then, this ion is accelerated, by applying a high-frequency AC voltage, and collides with a collision gas. The fragmentation ions generated are then detected by a mass scan. ${ }^{45}$ The collision energy needed to achieve optimum fragmentation efficiency has been shown to follow a linear correlation with $\mathrm{m} / \mathrm{z}$. The normalized collision energy (NCE) principle automatically compensates for this mass dependency. ${ }^{46}$ NCE levels of $10 \%, 20 \%, 30 \%$ and $40 \%$ were tested to establish the optimal NCE value that would allow, through $M^{2}$ spectra, analyzing the structural stability of the sample, as this parameter has been used to predict drug metabolites at given NCE values as recommended by the MS manufacturer (25\% or $30 \%$ ). 46,47

All spectra were only obtained in positive ionization mode, as compounds under study (basic nitrogen-containing molecules) are barely detectable in the negative ionization mode. Data were collected and analyzed by using the Xcalibur software developed by ThermoFinnigan.

\section{Sample preparation and injection}

Degassed methanolic solutions of the compounds, containing $0.1 \%$ acetic acid, were infused into the ESI probe at a rate 


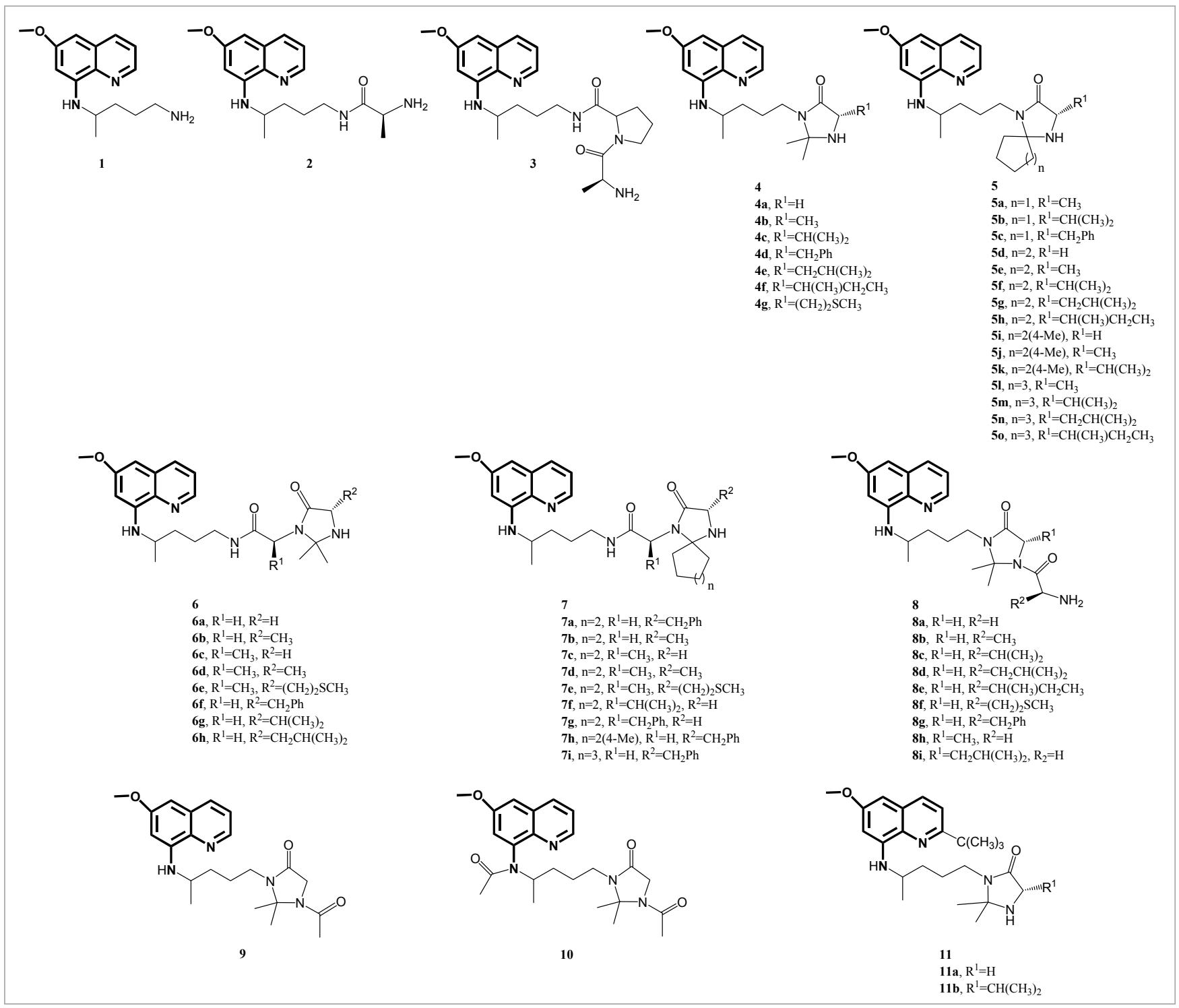

of $3 \mu \mathrm{L} \mathrm{min}{ }^{-1}$. Inclusion of methanol to prepare samples was necessary to obtain good electrospray behavior. ${ }^{48}$ For those derivatives bearing the amino acid methionine $(4 \mathrm{~g}, 6 \mathrm{e}$ and 8f), samples were also prepared in degassed acetonitrile and re-analyzed, to check the identity of methanol adducts detected in the previous analyses (cf. the section on In-source CID spectral analyses).

\section{Results and discussion In-source CID spectral analysis}

Previous comprehensive ESI-MS fragmentation studies on compounds $\mathbf{4}$ have revealed that acetone-derived imidazolidin-4-ones, especially smaller ones $\left(R^{1}=H, M e\right)$, are clearly more "fragmentable" in the NSR than those derived from cyclic ketones. ${ }^{21}$ This has now been confirmed with compounds $\mathbf{4 g}$ (PQMetAcetone, $\left.\mathrm{R}^{1}=\left(\mathrm{CH}_{2}\right)_{2} \mathrm{SMe}\right)$ and $5 \mathrm{e}$
(PQAlaC6, $\mathrm{R}^{1}=\mathrm{Me}$ ), not included in that previous work. While at high voltages one could observe two major fragmentations of $\mathbf{4 g}$ leading to peaks at $\mathrm{m} / \mathrm{z} 175$ (6-methoxy-8-aminoquinoline, MAQ) and $\mathrm{m} / \mathrm{z} 132$ (7,8-dihidroquinoline, DHQ), as previously reported for other compounds of the same series, ${ }^{21}$ the in-source CID spectrum of compound 5 e exclusively exhibited peaks from species $[\mathrm{M}+\mathrm{Na}]^{+}$and $[2 \mathrm{M}+\mathrm{Na}]^{+}$. The same general behavior in the NSR was found for the remaining series of $P Q$-derived imidazolidin-4-ones, that is, for compounds 6-8, as predominant species on the in-source CID spectra were basically the quasi-molecular ions of the original compound, $[\mathrm{M}+\mathrm{H}]^{+}$, its sodium adduct, $[\mathrm{M}+\mathrm{Na}]^{+}$, its dimer $\left[2 \mathrm{M}+\mathrm{H}^{+}\right.$, or the sodium adduct of the latter, $[2 \mathrm{M}+\mathrm{Na}]^{+}$, with major fragmentations corresponding to the release of MAQ $(\mathrm{m} / \mathrm{z} 175)$ or $\mathrm{DHQ}(\mathrm{m} / \mathrm{z} 132) .{ }^{22}$

An interesting observation concerning the behavior of compounds 4-8 in the NSR was the parallelism found between compound resistance to collision-induced fragmentation and 

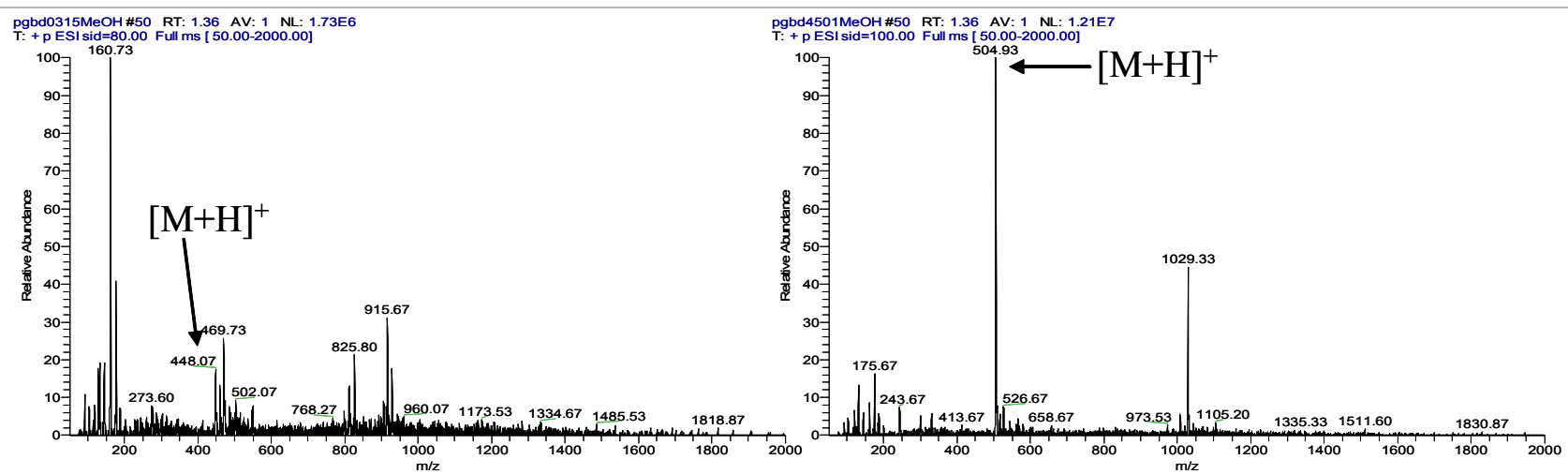

Figure 1. In-source CID spectra at $100 \mathrm{~V}$ of $4 \mathrm{~d}$ (left) and $8 \mathrm{~g}$ (right). Compound $4 \mathrm{~d}$ has $\mathrm{t}_{1 / 2}=31$ days in isotonic buffer at $\mathrm{pH} 7.4$ and $37^{\circ} \mathrm{C}$, whereas $8 \mathrm{~g}$ does not suffer any detectable degradation under identical conditions. ${ }^{15,16,19}$

their stability to hydrolysis at physiological $\mathrm{pH}$ and $T$. For instance, if we take the in-source CID spectra of compounds 4d (PQPheAcetone, $\mathrm{R}^{1}=\mathrm{Bz}$ ) and $\mathbf{8 g}$ (PQGlyAcetonePhe, $\mathrm{R}^{1}=\mathrm{H}$ and $\mathrm{R}^{2}=\mathrm{Bzl}$ ) at $100 \mathrm{~V}$ (Figure 1), we can see that $\mathbf{4 d}$ is clearly less stable than $\mathbf{8} \mathbf{g}$ in the NSR. Now, taking their behavior in isotonic buffer at physiological $\mathrm{pH}$ and $T, 15,16,19$ we find exactly the same trend. This strongly suggests that in-source CID spectra might work as a predictive tool for compound reactivity towards hydrolysis under physiological conditions.

We could also detect the minor formation, in the NSR, of dimeric structures derived from compounds 4,5 and $\mathbf{8}$, in this last case corresponding to the bonding of two identical monomers bridged by a methylene group $\left(\mathrm{m} / \mathrm{z}=2 \times \mathrm{m} / \mathrm{z}[\mathrm{M}+\mathrm{H}]^{+}+12\right){ }^{21,22}$ These findings are strikingly in line with reports from McChesney and co-workers, who have identified minor dimeric metabolites of $P Q$ produced by Streptomyces rimosus and Candida tropicalis, where two molecules of $N$-acetyl-PQ are bound together through either a direct biphenyl-like bridge between both quinoline $\mathrm{C}-5$ carbons or a methylene brigde between those same quinolinic carbons. ${ }^{49,50}$ Interestingly, compounds bearing the amino acid methionine ( $\mathbf{4 g}$ and $\mathbf{7 e}$ ) presented in-source CID spectra with an additional peak at $\mathrm{m} / z=m / z[\mathrm{M}+\mathrm{Na}]^{+}+32$ [(Figure 2(a)] when the samples were prepared in methanol. Ascribing such peaks to methanol adducts is the most obvious interpretation. Adduct formation must involve the Met sulphur atom, as identical adducts were not observed for any compounds where Met was absent. In fact, oxidative formation of covalent Met adducts with aromatic moieties, for example, catechols ${ }^{51}$ 3,5-dibromo4-nitrosobenzenesulphonic acid ${ }^{52}$ have been reported. An alternative explanation for the peak at $\mathrm{m} / \mathrm{z}=\mathrm{m} / \mathrm{z}[\mathrm{M}+\mathrm{Na}]^{+}+32$ would be Met oxidation in the course of the in-source CID experiments, as oxidation of the Met thioether to a sulfone is a current phenomenon in vivo, ${ }^{53-56}$ which is also chemically or photochemically inducible. ${ }^{57}$

To check which hypothesis was the correct one, new samples were prepared in acetonitrile and their spectra obtained, which allowed observing the disappearance of the $\mathrm{m} / \mathrm{z}=\mathrm{m} / \mathrm{z}$ $[\mathrm{M}+\mathrm{Na}]^{+}+32$ peak [Figure $\left.2(\mathrm{~b})\right]$, providing the proof that this was in fact due to formation of methanol adducts.
Another relevant aspect about the physicochemical properties of the title compounds, which could be traced by ESI-MS analysis in the NSR, concerned the presence or absence of ionizable (proton-donating) amino groups in the analyzed structures. Ionizable groups/hydrogen-bonding pairs are known to play key roles in many chemical and enzymatic reactions. In the case of PQ-derived imidazolidin-4-ones, we set out to analyze the effect of blocking one or both secondary amino groups in structures 4 . This was done by acetylation of one or both the relevant secondary amines in 4 a (PQGlyAcetone, $\mathrm{R}^{1}=\mathrm{H}$ ) to, respectively, yield structures 9 and $10 . \mathrm{N}$-acetylation led to an increase in compound stability towards collisioninduced dissociation in the NSR, as depicted for compound 10 in Figure 3, where only the sodium adduct of the quasimolecular ion of the original species, $[\mathrm{M}+\mathrm{Na}]^{+}$, or its dimer, $[2 \mathrm{M}+\mathrm{Na}]^{+}$, were seen as predominant species at voltages from $10 \mathrm{~V}$ to $100 \mathrm{~V}$.

\section{MS/MS analysis}

General fragmentation pathways and application to isomer identification

MS/MS analysis was tested at four different NCE, which detected that all imidazolidin-4-ones underwent visible fragmentation only at NCE $\geqslant 30 \%$, corroborating the high stability observed in the NSR (see the section on In-source CID spectral analysis)). Moreover, all compounds studied, with the exception of $\mathbf{8}$ and 10 , had loss of $M A Q^{21,22}$ as the most relevant fragmentation, as the base-peak of all $\mathrm{MS}^{2}$ spectra was invariably observed at $m / z=m / z[M+H]^{+}-174$.

In the case of $M^{2}$ spectra of 8 at NCE $=30 \%$, the basepeak was invariably found at $m / z=300$, independently of the exact structure of the compound, i.e. of the identity of substituent groups $R^{1}$ and $R^{2}$. This was a very important finding, as it constitutes a major difference between compounds 8 and their isomers 6 , showing that ESI-MS ${ }^{2}$ analysis of these kinds of structure may become a useful tool for isomer identification. The rationale for the different behavior of compounds 6 vs 8 was based on the disruption of the imidazolidin-4-one ring of 8 to yield the iminium ion 


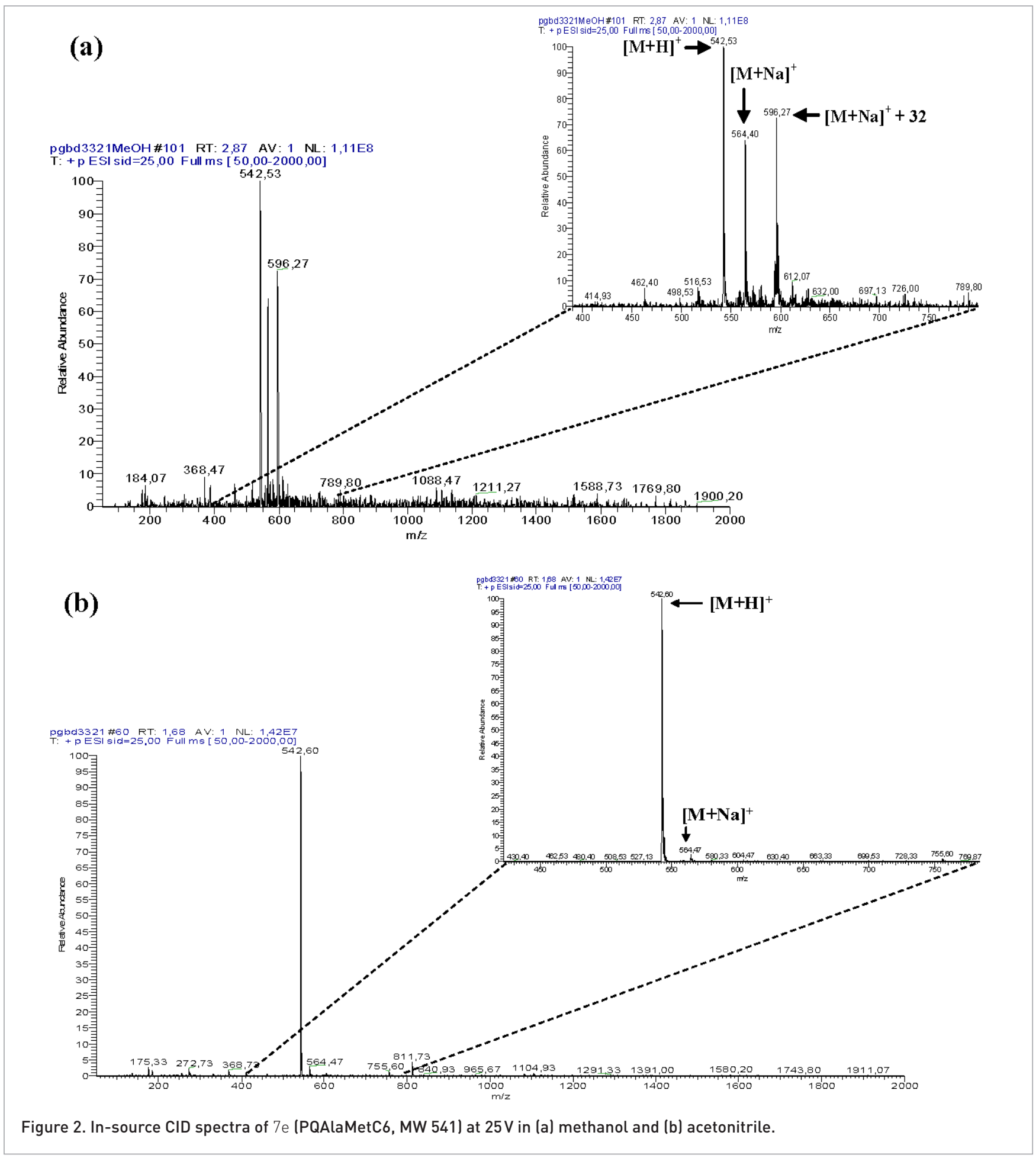

12 (Scheme 1) that readily undergoes a cyclization-elimination reaction to produce the detected propyliminium ion 13 and a neutral diketopiperazine (DKP, 14). This fragmentation pathway is similar to that described as the "diketopiperazine pathway" for MS/MS backbone fragmentations of oligopeptides ${ }^{58-66}$ and, as mentioned before, can be regarded as a valuable instrument for unequivocal distinction between terminal (6, PQXaaPro mimetics) and "internal" (8, PQProXaa mimetics) imidazolidin-4-one isomers. ${ }^{22}$

Levels of unfragmented original species and application to stability predictions

Another analyzed parameter was the relative abundance of the original (unfragmented) species still detected on $\mathrm{MS}^{2}$ spectra 

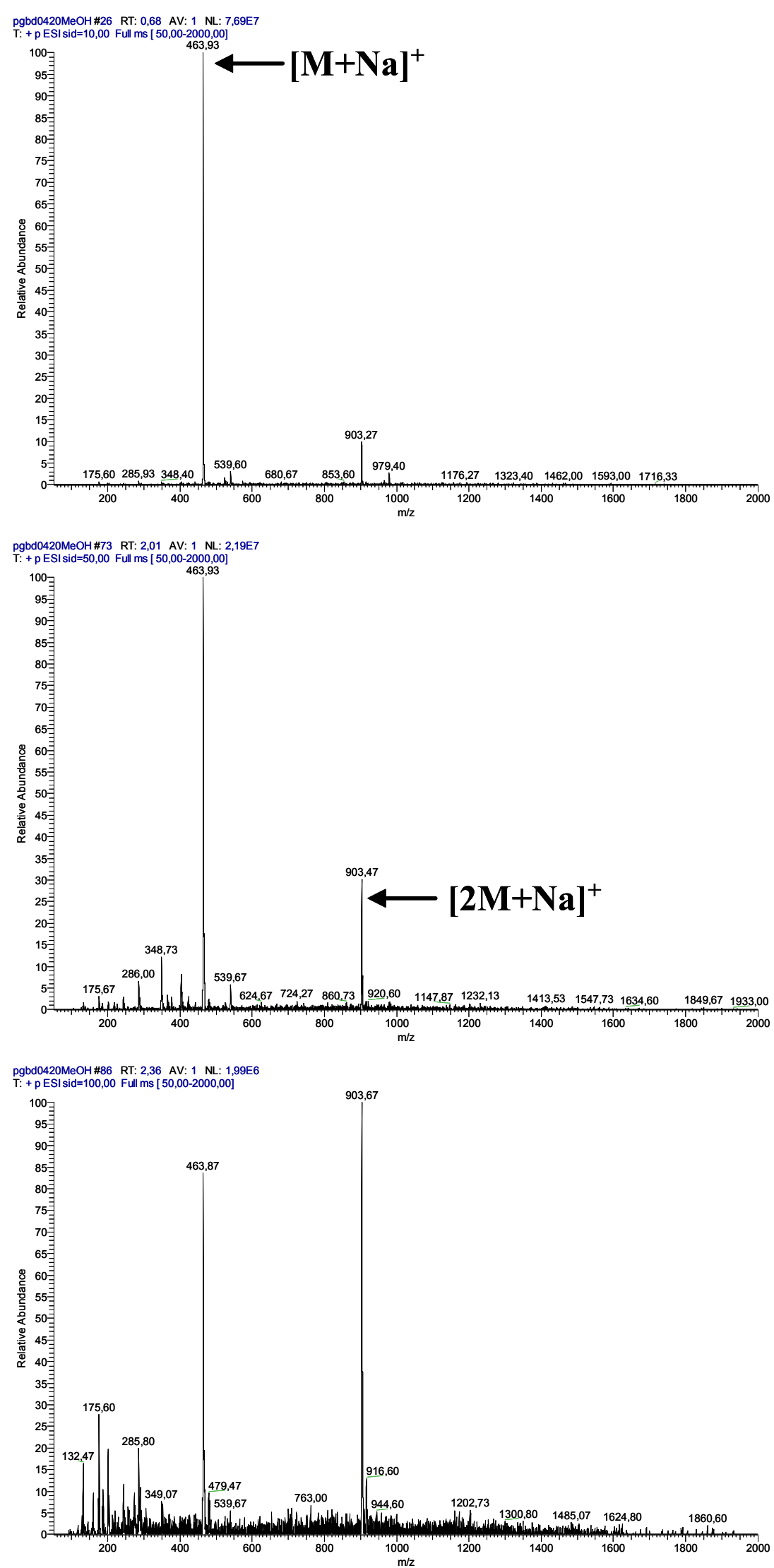

Figure 3. In-source CID spectra for 10 (MW 440) on the NSR at 10V (top), 50 V (middle) and 100 V (bottom). 


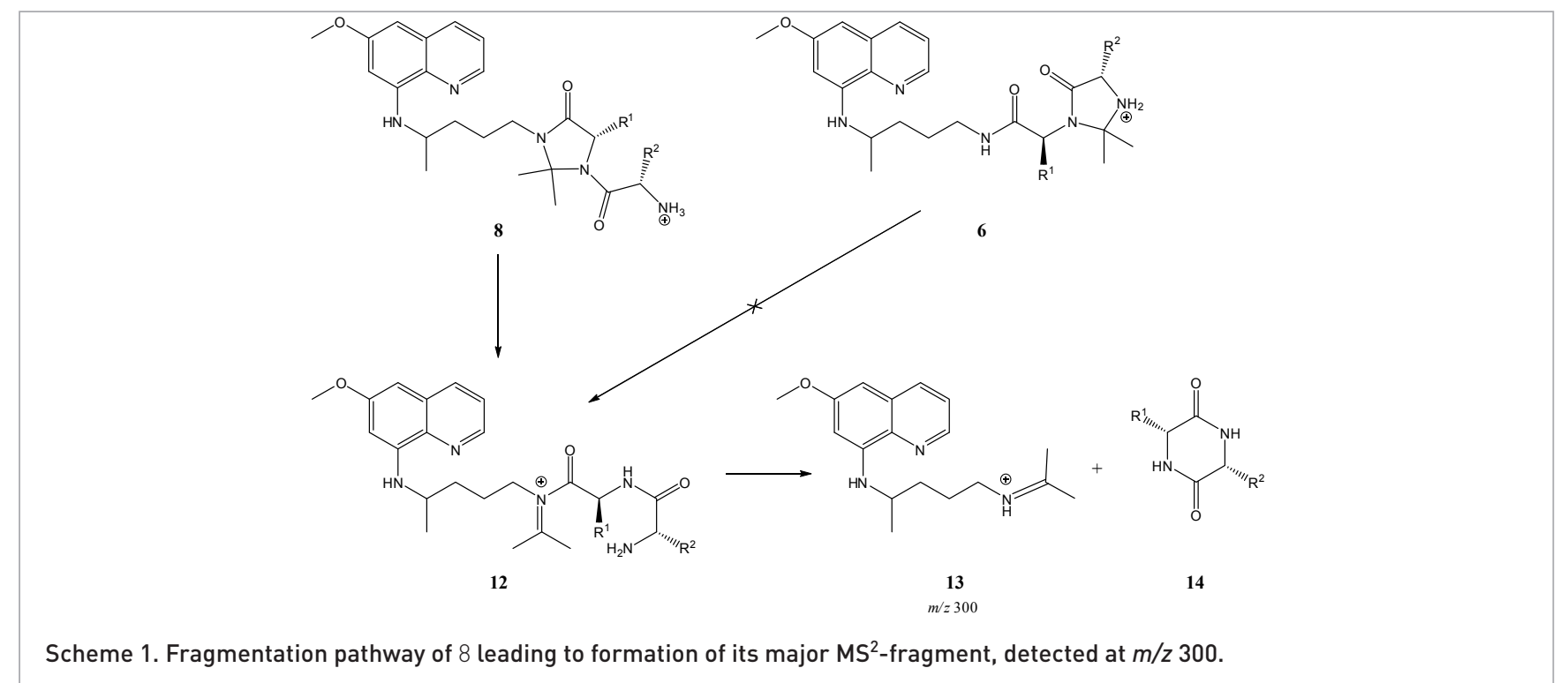

at $\mathrm{NCE}=30 \%$ for those compounds sharing identical major fragmentation phenomena (loss of $M A Q$ or $2{ }^{t} B u-M A Q$ ). As shown in Table 1, both the parent drug, 1, and its 2-tert-butyl derivative, $B P Q$, were quantitatively fragmented under these conditions (Figure 4), therefore being the least stable of the set. On the other hand, their imidazolidin-4-one derivatives followed the stability order $\mathbf{1 1}>\mathbf{4}>\mathbf{6}$. This ranking agrees with our findings on the relative stability of compounds $\mathbf{4}$ and $\mathbf{6}$ towards hydrolysis at physiological $\mathrm{pH}$ and $T^{15,16,19,20}$ again suggesting that ESI-MS fragmentation behavioral patterns might work as a predictor tool for compound stability in aqueous media.

Interestingly, while insertion of the 2-tert-butyl substituent in $P Q$ did not seem to exert any stabilizing effect, the opposite was found when considering the corresponding imidazolidin4-one derivatives 11 and $4 \mathrm{a}$. Although the physico-chemical meaning of such a difference is not evident, 11 is clearly more stable towards fragmentation than $\mathbf{4 a}$ (Figure 5).

Compounds 8 had a markedly different major fragmentation pathway and, therefore, were excluded from this evaluation. In the case of the acetyl derivatives 9 and 10, these were practically intact at NCE 30\% (relative abundance of the original species $\approx 100 \%$ ), reinforcing that $N$-acetylation produces highly stable molecules.
Correlation between imidazolidin-4-one ring stability in MS/MS and useful physicochemical descriptors

In our most recent work on compounds 8 as PQProXaa mimetics, we came across a striking observation concerning the fact that the relative abundance of an important $M S^{2}$-fragment was inversely proportional to the size of the side chain in the variable amino acid Xaa. ${ }^{22}$ This was reflected by a perfectly linear correlation $l y=-0.66 v+2.33 ; r^{2}=0.997$, $n=5$ ) between the logarithm of the fragment's relative abundance $(y)$ and the Charton parameter, $\nu,{ }^{67}$ associated to the side chain of each different Xaa. ${ }^{22}$ These findings prompted us to engage into an empirical search for other correlations between $\mathrm{MS}^{2}$-fragmentation behavior of the other two families of $P Q$ imidazolidin-4-ones, namely, PQPro mimetics (represented by series $\mathbf{4}$ and $\mathbf{5}$ ) and PQXaaPro mimetics (represented by series 6 and 7) with relevant physico-chemical descriptors. Results obtained are described below.

Imidazolidin-4-one ring opening in PQPro mimetics In order to establish a parallel for imidazolidin-4-one ring opening in aqueous media, ${ }^{16}$ we set out to explore the extent of $M^{2}{ }^{2}$-induced ring opening on a series of compounds 5 , taken

Table 1. Relative abundance of the original species at NCE $=30 \%$ on $\mathrm{MS}^{2}$.

\begin{tabular}{|c|l|c|}
\hline Compound & Abbreviation & $\begin{array}{c}\text { \% initial compound } \\
\text { after } \text { MS }^{2} \text { fragmentation }\end{array}$ \\
\hline 2- ${ }^{\mathrm{t}}$ Bu-primaquine & BPQ & 0 \\
\hline 1 & $P Q$ & 0 \\
\hline $6 a$ & $P Q G l y G l y A c e t o n e$ & 10.40 \\
\hline $4 a$ & PQGlyAcetone & 23.86 \\
\hline $11 a$ & BPQGlyAcetone & 71.27 \\
\hline
\end{tabular}



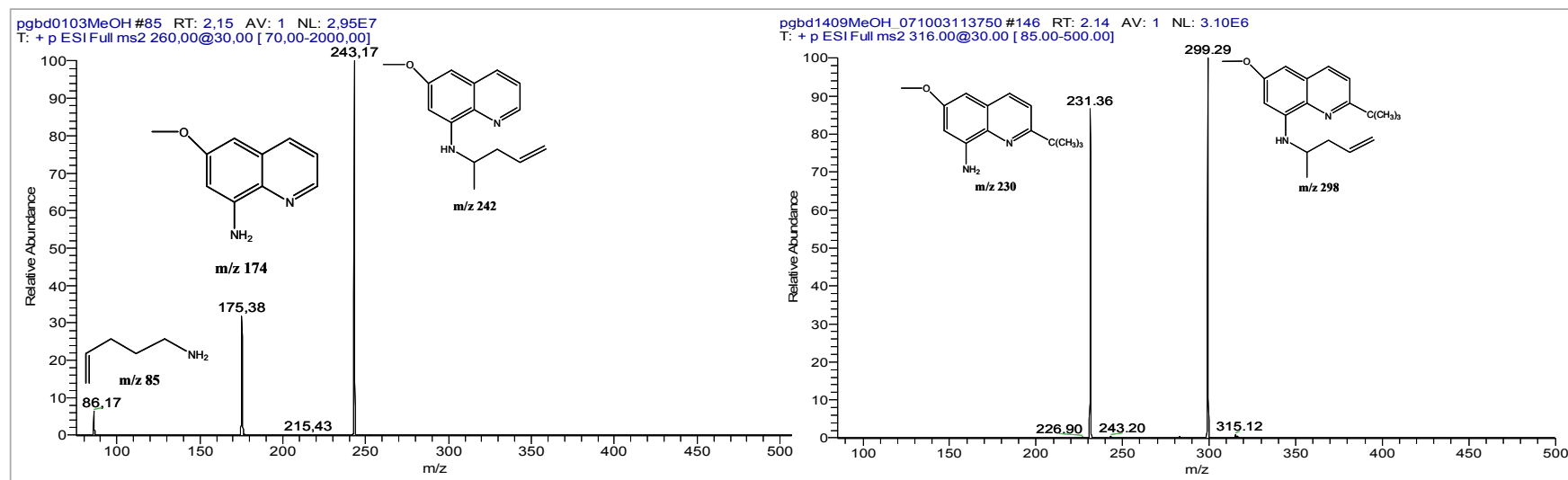

Figure 4. $\mathrm{MS}^{2}$ spectra for $\mathrm{PQ}$ (left) and $\mathrm{BPQ}$ (right) at $\mathrm{NCE}=30 \%$.
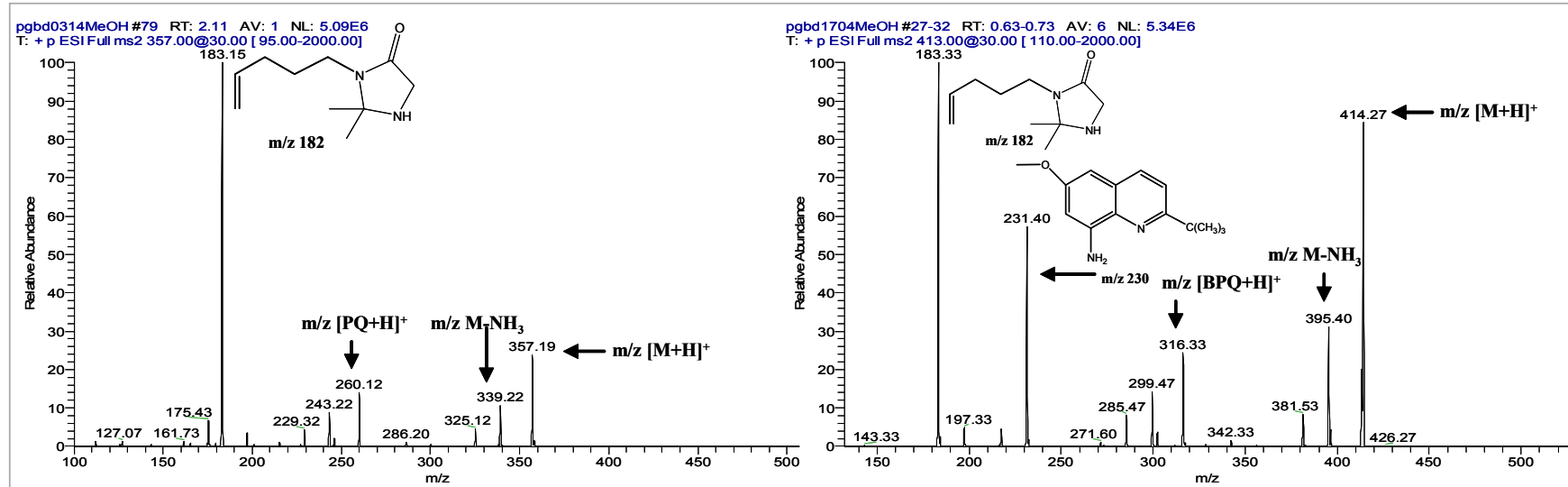

Figure 5. $\mathrm{MS}^{2}$ spectra for compounds $4 \mathrm{a}$ (left) and $11 \mathrm{a}$ (right) at NCE $=30 \%$.

as representative of PQPro mimetics. This series was chosen to include different amino acids whose side chains $\left(R^{1}\right)$ are associated to distinct values of the Charton steric parameter, $\nu$. Previous studies have shown that protonated $P Q$ imidazolidin-4-ones undergo ring opening in aqueous buffers at $60^{\circ} \mathrm{C}$ in a fashion similar to the first step on Scheme $2{ }^{16}$ which was recently confirmed for compounds 6 and $7 .{ }^{19}$ Therefore, we hypothesized that such ring opening could easily occur in the course of $\mathrm{MS}^{2}$-fragmentations, being followed by ammonia loss to yield ion 15. This hypothesis was based on the fact that ammonia loss is a common phenomenon on $\mathrm{MS}^{n}$-induced fragmentations of peptides and amino acid derivatives ${ }^{68-70}$ including those bearing Xaa-Pro moieties. ${ }^{71}$ Indeed, every $M^{2}$ spectrum of the compound series analyzed displayed a peak compatible with structure 15 , which reinforced our assumption. Consequently, we considered that the abundance of 15 could reflect the compound's relative stability and be used to find any correlation between compound stability and structure.

The log of the relative abundance of 15 was represented against the value of $v$ associated to each $\mathrm{R}^{1}$ (Table 2), resulting in the perfectly linear correlation displayed on Figure 6.

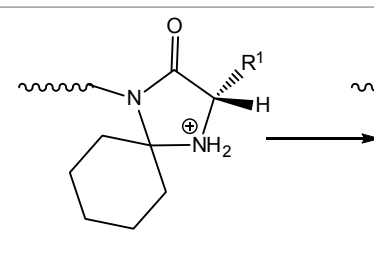

5<smiles>[R]CC(=O)N(CCCC)C(=O)C[R]</smiles>

15

Scheme 2. Imidazolidin-4-one ring opening after protonation of its secondary amine, to yield ion 15. 
Table 2. Relative abundance of species $15\left(\mathrm{MH}^{+}-17\right)$ resulting from $\mathrm{MS}^{2}$ fragmentation of compounds $5 \mathrm{~d}, 5 \mathrm{e}, 5 \mathrm{f}$ and $5 \mathrm{~h}$ at $N C E=30 \%$ and the Charton steric parameter, $\nu^{67}$ associated to each $\mathrm{R}^{1}$.

\begin{tabular}{|c|l|l|c|c|c|}
\hline Compound & Abbreviation & \multicolumn{1}{|c|}{$\mathbf{R}^{1}$} & $\begin{array}{c}\text { Charton steric parameter } \\
\text { for } \mathbf{R}^{1}, v\end{array}$ & $\begin{array}{c}\text { Relative abundance } \\
\text { (\%) of } \mathbf{1 5}\end{array}$ & $\begin{array}{c}\text { log (relative } \\
\text { abundance) }\end{array}$ \\
\hline $5 \mathbf{d}$ & PQGlyC6 & $\mathrm{H}$ & 0 & 33.36 & 1.52 \\
\hline $5 \mathrm{e}$ & PQAlaC6 & $\mathrm{CH}_{3}$ & 0.52 & 16.08 & 1.21 \\
\hline $5 \mathbf{f}$ & PQValC6 & $\mathrm{CH}_{\left(\mathrm{CH}_{3}\right)_{2}}$ & 0.76 & 10.67 & 1.03 \\
\hline $5 \mathrm{~h}$ & PQlleC6 & $\mathrm{CH}\left(\mathrm{CH}_{3}\right) \mathrm{CH}_{2} \mathrm{CH}_{3}$ & 1.02 & 8.68 & 0.94 \\
\hline
\end{tabular}

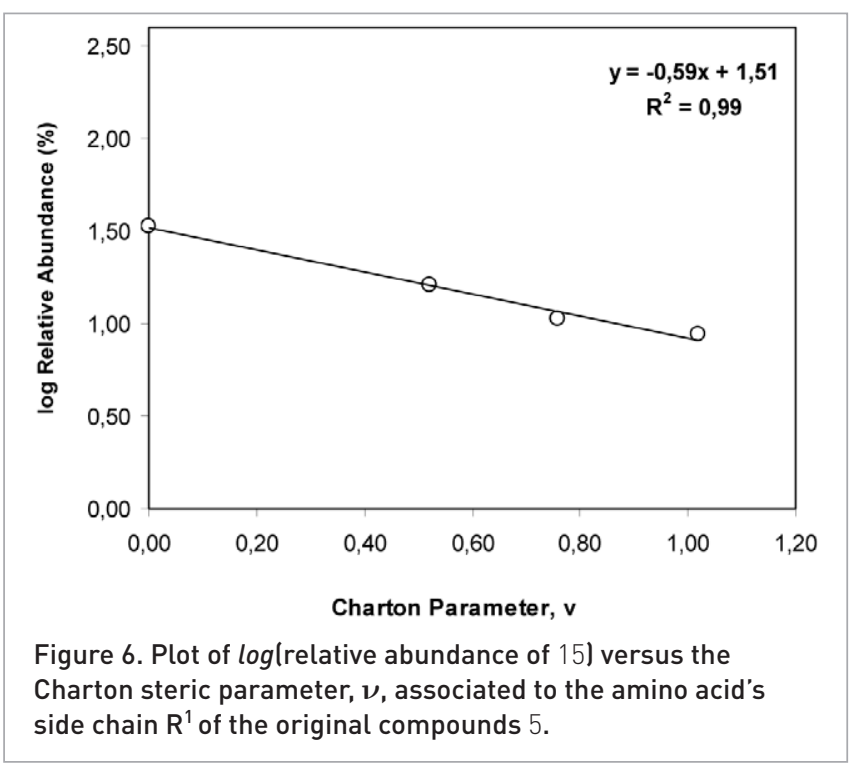

The negative slope obtained indicates that steric crowding imposed by the amino acid's side chain $\mathrm{R}^{1}$ does not favor, or delays, the formation of ion 15. This is astonishingly coincidental with our previous findings in aqueous medium, as reported in Reference 16. In this former work, a parallel correlation was found, for the same compounds, between $\log k_{\text {neut }}$ (apparent first-order rate constant for ring opening in the neutral imidazolidin-4-ones 5 ) and the Charton steric parameter $\left(\log k_{\text {neut }}=-1.30 \nu-0.75 ; r^{2}=0.993, n=4\right) .{ }^{16}$ This is a relevant finding, as there is no other example in the literature where parallel quantitative structure-reactivity correlations have been found between compound reactivity in solution under mild conditions laqueous media at physiological pH and $T$ ) and compound fragmentation behavior in the course of MS/MS experiments based on ESI techniques. These findings open a whole new perspective on the application of ESI-MS techniques to the characterization of drugs bearing an imidazolidin-4-one or similar structural motif.

Imidazolidin-4-one ring opening in PQXaaPro mimetics Motivated by the above results, we searched for similar correlations in PQXaaPro mimetics, taking compounds 6 as representative of this family. To that purpose, we selected the most relevant fragment reflecting imidazolidin-4-one ring disruption on compounds 6 , associated with an $\mathrm{m} / \mathrm{z}$ value $75 \mathrm{amu}$ lower than that of the corresponding unfragmented quasimolecular ion $[\mathrm{M}+\mathrm{H}]^{+} .{ }^{22}$ Such mass loss corresponds to ring opening with the departure of isopropylamine plus dehydration, to yield ion 16 , so we took the relative abundance of this ion as an indirect measure of the relative ring stabilities within a subset of compounds 6 having Gly directly attached to $P Q$ $\left(R^{1}=H\right)$ and varying amino acids forming the imidazolidin4-one ring $\left(\mathrm{R}^{2}=\mathrm{H}, \mathrm{Me}, \mathrm{Bzl}, i \operatorname{Pr}\right.$ and $\left.i \mathrm{Bu}\right)$.<smiles>COc1cc(NC(C)C)c2ncccc2c1</smiles>

The correlation between the relative abundance of ion 16 , for the subset mentioned above, and the value of $v$ associated to each $R^{2}$, was analyzed (Table 3 ). The relative abundance of 16

Table 3. Relative abundance of species 16 resulting from $\mathrm{MS}^{2}$ fragmentation of compounds $6 \mathrm{a}, 6 \mathrm{~b}, 6 \mathrm{f}, 6 \mathrm{~g}$ and $6 \mathrm{~h}$ at $\mathrm{NCE}=30 \%$ and $\mathrm{Charton}$ steric parameters, $\nu,{ }^{67}$ associated to each $\mathrm{R}^{2}$.

\begin{tabular}{|c|c|c|c|c|c|}
\hline Compound & Abbreviation & $\mathrm{R}^{2}$ & $\begin{array}{c}\text { Charton steric } \\
\text { parameter for } R^{1}, \nu\end{array}$ & $\begin{array}{l}\text { Relative abundance } \\
(\%) \text { of } 16\end{array}$ & $\begin{array}{l}\text { log (relative } \\
\text { abundance) }\end{array}$ \\
\hline 6.1 & \multirow[t]{5}{*}{ PQGlyaa2Acetone } & $\mathrm{H}$ & 0 & 18.68 & 1.27 \\
\hline 6.2 & & $\mathrm{CH}_{3}$ & 0.52 & 13.53 & 1.17 \\
\hline 6.6 & & $\mathrm{CH}_{2} \mathrm{Ph}$ & 0.70 & 12.15 & 1.08 \\
\hline 6.7 & & $\mathrm{CH}\left(\mathrm{CH}_{3}\right)_{2}$ & 0.76 & 10.15 & 1.01 \\
\hline 6.8 & & $\mathrm{CH}_{2} \mathrm{CH}\left(\mathrm{CH}_{3}\right)_{2}$ & 0.98 & 9.63 & 0.98 \\
\hline
\end{tabular}




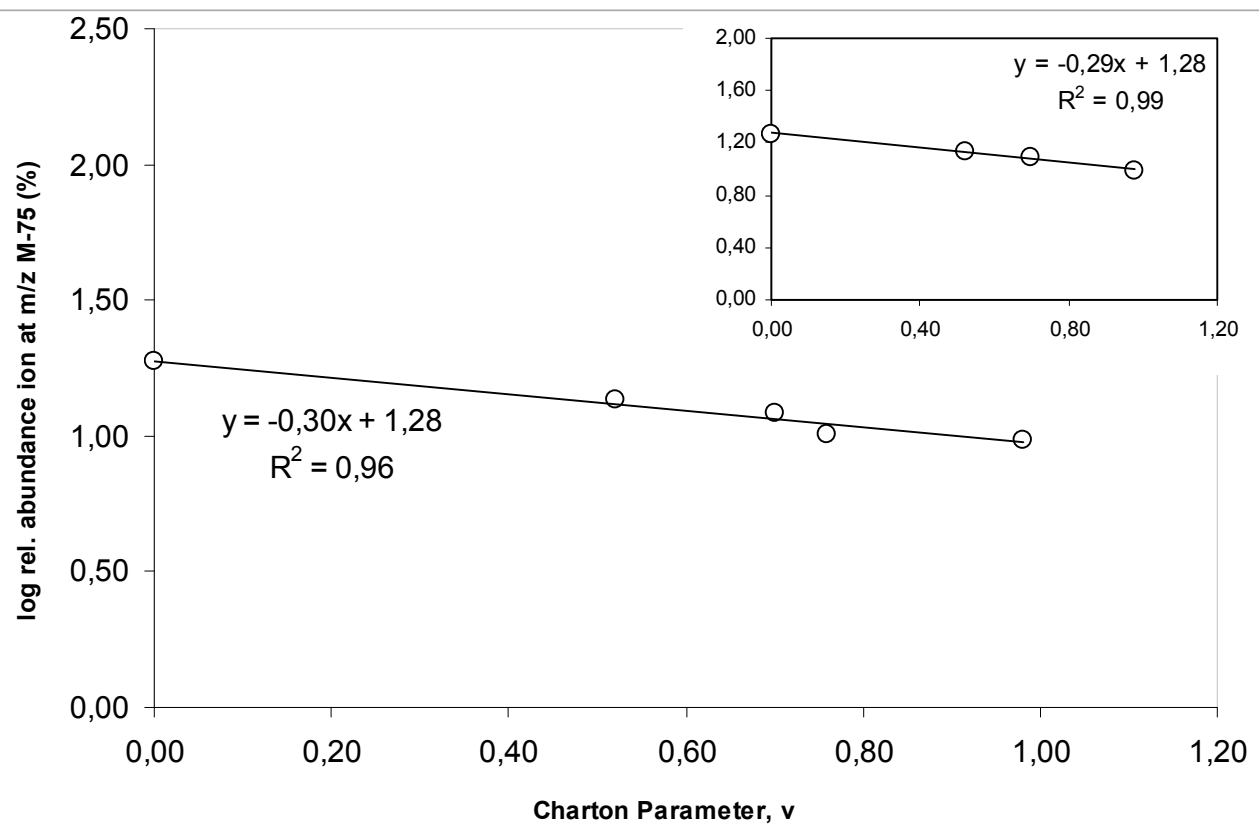

Figure 7. Plot of $\log \left(\right.$ relative abundance of 16 ) versus the Charton steric parameter, $\nu$, associated to the amino acid's side chain $R^{2}$ of the original compounds 6 . The insert shows the plot obtained when $6 \mathrm{~g}$ is excluded from the correlation analysis.

was again inversely proportional to the size of $\mathrm{R}^{2}$. The linear fit is very good if all the five points are considered $\left(r^{2}=0.96, n=5\right)$ and becomes excellent when one of those points $\left(R^{2}=i \mathrm{Pr}\right)$ is excluded $\left(r^{2}=0.99, n=4\right)$, reinforcing the significance of the correlation found (Figure 7). Once more, this correlation perfectly matches our previous findings concerning the relative rates of ring opening for compounds 6 in an aqueous medium. ${ }^{19}$

Finally, we would like to stress that four to five different compounds were used to establish each one of the above correlations, as the use of four to five experimental points is a common procedure to establish these kinds of structure-[re]activity correlation in therapeutically relevant compounds. ${ }^{72-75}$

\section{Conclusion}

In-source CID and MS/MS spectral analyses of peptidomimetic imidazolidin-4-one derivatives of an antimalarial drug, primaquine, were carried out and are described in the present report. In-source CID spectra were found to reflect the overall compound's relative reactivity under physiological conditions, as compared to data from previous stability studies in aqueous media. Moreover, MS/MS analysis provided a means to distinguish between isomeric PQXaaPro and PQProXaa mimetics, as key fragmentations were different between both families, which only differed at the position where the imidazolidin4-one ring was inserted. Last, but not least, correlations were found between the relative abundances of key $\mathrm{MS}^{2}$-generated fragments and relevant physico-chemical descriptors, namely, the Charton steric parameter associated to amino acid side chains. To the best of our knowledge, nothing of this kind has been reported by others.

Overall, the present work is relevant to consolidate ESI-MS as a key tool for drug analysis and characterization. Specifically in what concerns therapeutically relevant agents bearing the imidazolidin-4-one scaffold or related peptidomimetic structural motifs, our findings show that ESI-MS techniques, both through in-source CID spectra or MS/MS analysis, are reliable tools for stability predictions in aqueous media at physiological pH and $T$, providing that a suitable choice of key fragmentations is made. As far as we know, this type of correlation analysis has never been approached by other authors.

\section{Acknowledgments}

Thanks are due to Fundação para a Ciência e a Tecnologia (FCT, Portugal) for financial support through Project PTDC/ QUI/65142/2006. NV thanks FCT for Post-Doctoral fellowship SFRH/BPD/48345/2008. PG and RM thank FCT for support through pluriannual funding to CIQUP and 'Med.UL, respectively.

\section{References}

1. M. Yamashita and J.B. Fenn, "Negative ion production with the electrospray ion source", J. Phys. Chem. 88, 4671 (1984). doi: 10.1021/j150664a046

2. W.F. Smyth, "Electrospray ionisation-mass spectrometry (ESI-MS) and liquid chromatography-electrospray ionisation-mass spectrometry (LC-ESI-MS) of selected 
pharmaceuticals", Curr. Pharm. Anal. 2, 299 (2006). doi: 10.2174/157341206777934644

3. B.L. Tekwani and L.A. Walker, "8-Aminoquinolines: future role as antiprotozoal drugs", Curr. Opin. Infect. Dis. 19, 623 (2006). doi: 10.1097/QC0.0b013e328010b848

4. L.J.C. Bolchoz, R.A. Budinsky, D.C. Mcmillan and D.J. Jollow, "Primaquine-induced hemolytic anemia: formation and hemotoxicity of the arylhydroxylamine metabolite 6-methoxy-8-hydroxylaminoquinoline", J. Pharmacol, Exp. Ther. 297, 509 (2001).

5. G.W. Mihaly, S.A. Ward, G. Edwards, M. L'Eorme and A.M. Breckenridge, "Pharmacokinetics of primaquine in man: identification of the carboxylic acid derivative as a major plasma metabolite", Br. J. Clin. Pharmacol. 17, 441 (1984).

6. L. Constantino, P. Paixão, R. Moreira, M.J. Portela, V.E. do Rosário and J. Iley, "Metabolism of primaquine by liver homogenate fractions. Evidence for MAO and Cyt P450 involvement in the oxidative deamination of primaquine to carboxyprimaquine", Exp. Toxic. Pathol. 51, 299 (1999).

7. J. Hofsteenge, A. Capuano, R. Altszuler and S. Moore, "Carrier-linked primaquine in the chemotherapy of malaria", J. Med. Chem. 29, 1765 (1986). doi: $10.1021 /$ jm00159a034

8. A. Philip, J.A. Kepler, B.H. Johnson and F.I. Carroll, "Peptide derivatives of primaquine as potential antimalarial agents", J. Med. Chem. 31, 870 (1988). doi: 10.1021/ im00399a032

9. R. Borissova, B. Lammek, P. Stjärnkvist and I. Sjöholm, "Biodegradable microspheres. 16. Synthesis of primaquine-peptide spacers for lysosomal release from starch microparticles", J. Pharm. Sci. 84, 249 (1995). doi: 10.1002/jps. 2600840226

10. R. Borissova, P. Stjärnkvist, M.O. Karlsson and I. Sjöholm, "Biodegradable microspheres. 17. Lysosomal degradation of primaquine-peptide spacer arm", J. Pharm. Sci. 84, 256 (1995). doi: 10.1002/jps. 2600840227

11. M.C. Chung, M.F. Gonçalves, W. Colli, E.I. Ferreira and M.T.M. Miranda, "Synthesis and in vitro evaluation of potential antichagasic dipeptide prodrugs of primaquine", J. Pharm. Sci. 86, 1127 (1997). doi: 10.1021/js970006v

12. M.J. Portela, R. Moreira, E. Valente, L. Constantino, J. Iley, J. Pinto, R. Rosa, P. Cravo and V.E. do Rosário, “Dipeptide derivatives of primaquine as transmissionblocking antimalarials: effect of aliphatic side-chain acylation on the gametocytocidal activity and on the formation of carboxyprimaquine in rat liver homogenates", Pharm. Res. 16, 949 (1999). doi: 10.1023/A:1018922425551

13. S. Romeo, M. Dell'Agli, S. Parapini, L. Rizzi, G. Galli, M. Mondani, A. Sparatore, D. Taramelli and E. Bosisio, "Plasmepsin II inhibition and antiplasmodial activity of Primaquine-Statine "double-drugs", Bioorg. Med. Chem. Lett. 14, 2931 (2004). doi: 10.1016/j.bmcl.2004.03.030

14. P. Gomes, M.J. Araújo, M. Rodrigues, N. Vale, Z. Azevedo, J. Iley, P. Chambel, J. Morais and R. Moreira, "Synthesis of imidazolidin-4-one and $1 \mathrm{H}$-imidazo[2,1-a]isoindole-
2,5(3H,9bH)-dione derivatives of primaquine: scope and limitations", Tetrahedron 60, 5551 (2004). doi: 10.1016/j. tet.2004.04.077

15. M.J. Araújo, J. Bom, R. Capela, C. Casimiro, P. Chambel, P. Gomes, J. Iley, F. Lopes, J. Morais, R. Moreira, E. de Oliveira, V. do Rosário and N. Vale, "Imidazolidin-4one derivatives of primaquine as novel transmissionblocking antimalarials", J. Med. Chem. 48, 888 (2005). doi: $10.1021 / \mathrm{jm} 0494624$

16. P. Chambel, R. Capela, F. Lopes, J. Iley, J. Morais, L. Gouveia, J.R.B. Gomes, P. Gomes and R. Moreira, "Reactivity of imidazolidin-4-one derivatives of primaquine: implications for prodrug design", Tetrahedron 62, 9883 (2006). doi: 10.1016/j.tet.2006.08.026

17. R. Ferraz, J.R.B. Gomes, E. de Oliveira, R. Moreira and P. Gomes, "Unanticipated stereoselectivity in the reaction of primaquine alpha-aminoamides with substituted benzaldehydes: computational and experimental study", J. Org. Chem. 72, 4189 (2007). doi: 10.1021/j00703202

18. N. Vale, M.S. Collins, J. Gut, R. Ferraz, P.J. Rosenthal, M.T. Cushion, R. Moreira and P. Gomes, "AntiPneumocystis carinii and antiplasmodial activities of primaquine-derived imidazolidin-4-ones", Bioorg. Med. Chem. Lett. 18, 485 (2008). doi: 10.1016/j. $\underline{\text { bmcl.2007.11.105 }}$

19. N. Vale, F. Nogueira, V.E. do Rosário, P. Gomes and R. Moreira, "Primaquine dipeptide derivatives bearing an imidazolidin-4-one moiety at the $\mathrm{N}$-terminus as potential antimalarial prodrugs", Eur. J. Med. Chem. 44, 2506 (2009). doi: 10.1016/j.ejmech.2009.01.018

20. N. Vale, J. Matos, J. Gut, F. Nogueira, V. do Rosário, P.J. Rosenthal, R. Moreira and P. Gomes, "Imidazolidin-4one peptidomimetic derivatives of primaquine: Synthesis and antimalarial activity", Bioorg. Med. Chem. Lett. 18, 4150 (2008). doi: 10.1016/i.bmcl.2008.05.076

21. N. Vale, R. Moreira and P. Gomes, "Characterization of primaquine imidazolidin-4-ones with antimalarial activity by electrospray ionization-ion trap mass spectrometry", Int. J. Mass Spectrom. 270, 81 (2008). doi: 10.1016/j. ijms.2007.12.006

22. N. Vale, J. Matos, R. Moreira and P. Gomes, "Electrospray ionization-ion trap mass spectrometry study of PQAAPro and PQProAA mimetic derivatives of the antimalarial primaquine", J. Am. Soc. Mass Spectrom. 19, 1476 (2008). doi: 10.1016/j. jasms.2008.06.019

23. S.K. Kokpol, S.V. Hannongbua, N. Thongrit, S. Polman, B.M. Rode and M.G. Schwendinger, "Analysis of structure activity for primaquine antimalarial-drugs by quantum pharmacological approach", Anal. Sci. 4, 565 (1988). doi: 10.2116/analsci.4.565

24. S. Kristensen, L. Grinberg and H.H. Tønnsen, "Photoreactivity of biologically active compounds: XI. Primaquine and metabolites as radical inducers", Eur. J. Pharm. Sci. 5, 139 (1997). doi: 10.1016/S09280987(97)00268-6 
25. V.K. Dua, S.N. Sinha and V.P. Sharma, "Chromatographic studies of peroxydisulphate oxidation products of primaquine", J. Chromatogr. B 708, 316 (1998). doi: 10.1016/S0378-4347(97)00639-7

26. S. Kristensen, K. Nord, A.L. Orsteen and H.H. Tønnsen, "Photoreactivity of biologically active compounds, XIV: influence of oxygen on light induced reactions of primaquine", Pharmazie 53, 98 (1998). doi: $\underline{10.2116 /}$ analsci.18.595

27. T. Koide and K. Ueno, "Enantiomeric separations of cationic and neutral compounds by capillary electrochromatography with monolithic chiral stationary phases of $\beta$-cyclodextrin-bonded negatively charged polyacrylamide gels", J. Chromatogr. A 893, 177 (2000). doi: 10.1016/S0021-9673(00)00699-3

28. C. Zhang, C. Zhu, X. Lin, F. Gao and Y. Wei, “Enantiomeric separation of primaquine, an anti-malarial drug, by cyclodextrin-modified micellar electrokinetic capillary chromatography", Anal. Sci. 18, 595 (2002). doi: 10.2116/ analsci.18.595

29. J. Lal, N. Mehrotra and R.C. Gupta, "Analysis and pharmacokinetics of bulaquine and its major metabolite primaquine in rabbits using an LC-UV method-a pilot study", J. Pharm. Biomed. Anal. 32, 141 (2003). doi: $\underline{\text { 10.1016/S0731-7085(03)00033-5 }}$

30. A.K. Dwivedi, D. Saxena and S. Singh, "HPLC and HPTLC assays for the antimalarial agents chloroquine, primaquine and bulaquine", J. Pharm. Biomed. Anal. 33, 851 (2003). doi: 10.1016/S0731-7085(03)00355-8

31. S.N. Sinha and V.K. Dua, "Fast atom bombardment mass spectral analysis of three new oxidative products of primaquine", Int. J. Mass Spectrom. 232, 151 (2004). doi: 10.1016/j.ijms.2003.11.013

32. I. Brondz, D. Mantzilas, U. Klein, D. Ekeberg, E. Hvattum, M.N. Lebedeva, F.S. Mikhailitsyn, G.D. Souleimanov and J. Røe, "Nature of the main contaminant in the anti malaria drug primaquine diphosphate: a qualitative isomer analysis", J. Chromatogr. B 800, 211 (2004). doi: 10.1016/j.jchromb.2003.09.042

33. R. Bortocan and P.S. Bonato, "Enantioselective analysis of primaquine and its metabolite carboxyprimaquine by capillary electrophoresis", Electrophoresis 25, 2848 (2004). doi: $10.1002 /$ elps.200405961

34. S. Kristensen, "Photoreactivity of biologically active compounds. XVII. Influence of solvent interactions on spectroscopic properties and photostability of primaquine", Pharmazie 60, 426 (2005).

35. S. Bhoopathy, B. Xin, S.E. Unger and H.T. Karnes, "A novel incubation direct injection LC/MS/MS technique for in vitro drug metabolism screening studies involving the CYP 2D6 and the CYP 3 A4 isozymes", J. Pharm. Biomed. Anal. 37, 739 (2005). doi: 10.1016/j. ipba.2004.08.043

36. V.G. Dongre, P.P. Karmuse, M.M. Nimbalkar, D. Singh and A. Kumar, "Application of GC-El-MS for the identification and investigation of positional isomer in pri- maquine, an antimalarial drug", J. Pharm. Biomed. Anal. 39, 111 (2005). doi: 10.1016/j.jpba.2005.03.019

37. F. Zsila and G. Gedeon, "Binding of anti-prion agents to glycosaminoglycans: evidence from electronic absorption and circular dichroism spectroscopy", Biochem. Biophys. Res. Commun. 346, 1267 (2006). doi: 10.1016/j. bbrc. 2006.06 .033

38. M.A. La-Scalea, C.M.S. Menezes, G.C. Matsutami, M.C. Polli, S.H.P. Serrano and E.I. Ferreira, "Molecular modeling of the voltammetric oxidation at a glassy carbon electrode of the antimalarial drug primaquine and its prodrugs succinylprimaquine and maleylprimaquine", Electrochim. Acta 51, 5103 (2006). doi: 10.1016/j.electacta.2006.03.085

39. B. Avula, L.M. Tripathi, S.I. Khan, B.L. Tekwani, D. Nanayakkara, W. Gul, M.A. Elsohly and I.A. Khan, "LC method for the determination of NPC1161, primaquine and their metabolites in various biological systems", Chromatographia 64, 429 (2006). doi: 10.1365/s10337006-0049-x

40. I. Brondz, D. Ekeberg, D.S. Bell, A.R. Annino, J.A. Hustad, R. Svendsen, V. Vlachos, P. Oakley, G.J. Langley, T. Mohini, C.G. Amaury and F. Mikhalitsyn, "Nature of the main contaminant in the drug primaquine diphosphate: SFC and SFC-MS methods of analysis", J. Pharm. Biomed. Anal. 43, 937 (2007). doi: 10.1016/j. jpba.2006.09.017

41. V.G. Dongre, P.P. Karmuse, P.P. Rao and A. Kumar, "Development and validation of UPLC method for determination of primaquine phosphate and its impurities", J. Pharm. Biomed. Anal. 46, 236 (2008). doi: 10.1016/j. jpba.2007.09.012

42. N. Vale, J. Matos, R. Moreira and P. Gomes, "Amino acids as selective acylating agents: regiosselective $\mathrm{N}^{1}$-acylation of imidazolidin-4-one derivatives of the antimalarial drug primaquine", Tetrahedron 64, 11144 (2008). doi: $10.1016 /$ j.tet.2008.09.058

43. S. Vangapandu, S. Sachedva, M. Jain, S. Singh, P.P. Singh, L.C. Kaul and R. Jain, "8-Quinolinamines and their prodrug conjugates as potent blood-Schizontocidal antimalarial agents", Bioorg. Med. Chem. 11, 4557 (2003). doi: 10.1016/j.bmc.2003.07.003

44. M. Jain, S. Vangapandu, S. Sachdeva, S. Singh, P.P. Singh, G.B. Jena, K. Tikoo, P. Ramarao, C.L. Kaul and R. Jain, "Discovery of a bulky 2-tert-butyl group containing primaquine analogue that exhibits potent bloodschizontocidal antimalarial activities and complete elimination of methemoglobin toxicity", J. Med. Chem. 47, 285 (2004). doi: 10.1021/jm0304562

45. I. Slepukhina, T. Duelcks, H.M. Schiebel and D. Gabel, “Fragmentation of $\mathrm{B}_{12} \mathrm{H}_{11} \mathrm{~S}-\mathrm{R}(2-)$ in electrospray mass spectrometry, J. Organomet. Chem. 690, 2796 (2005). doi: $\underline{10.1016 / \text { i.jorganchem.2005.01.040 }}$

46. http://www.thermofinnigan.com

47. W.F. Smyth, J.C. Leslie, S. McClean, B. Hannigan, H.P. McKenna, B. Doherty, C. Joyce and E. O'Kane, "The 
characterisation of selected antidepressant drugs using electrospray ionisation with ion trap mass spectrometry and with quadrupole time-of-flight mass spectrometry and their determination by high-performance liquid chromatography/electrospray ionisation tandem mass spectrometry", Rapid Commun. Mass Spectrom. 20, 1637 (2006). doi: $10.1002 / \mathrm{rcm} .2485$

48. K.X. Wan, T. Shibue and M.L. Gross, "Non-covalent complexes between DNA-binding drugs and doublestranded oligodeoxynucleotides: a study by ESI ion-trap mass spectrometry", J. Am. Chem. Soc. 122, 300 (2000). doi: 10.1021/ja990684e

49. A.M. Clark, C.D. Hufford, R.K. Puri and J.D. McChesney, "Production of a novel dimeric metabolite of primaquine by Streptomyces rimosus”, App. Environ. Microbiol. 47, 540 (1984).

50. C.D. Hufford, A.M. Clark and J.D. McChesney, "Stereochemistry of dimeric microbial metabolites of primaquine", J. Org. Chem. 49, 2822 (1984). doi: $10.1021 /$ jo00189a039

51. M. Sugumaran and E. Nelson, "Model sclerotization studies. 4. Generation of N-acetylmethionyl catechol adducts during tyrosinase-catalyzed oxidation of catechols in the presence of $\mathrm{N}$-acetylmethionine", Arch. Insect. Biochem. Physiol. 38, 44 (1998). doi: $\underline{10.1002 /}$ (SICI)1520-6327(1998)38:1<44::AID-ARCH5>3.0.CO;2-V

52. D. Pietraforte and M. Minetti, "One-electron oxidation pathway of peroxynitrite decomposition in human blood plasma: evidence for the formation of protein tryptophan-centred radicals", Biochem. J. 321, 743 (1997).

53. W. Vost, "Oxidation of methionyl residues in proteins: Tools, targets, and reversal", Free Radical Biol. Med. 18, 93 (1995). doi: 10.1016/0891-5849(94)00158-G

54. H. Sun, J. Gao, D.A. Ferrington, H. Biesiada, T.D. Williams and T.C. Squaier, "Repair of oxidized calmodulin by methionine sulfoxide reductase restores ability to activate the plasma membrane Ca-ATPase", Biochemistry 38, 105 (1999). doi: 10.1021/bi981295k

55. J. Moskovitz, H. Weissbach and N. Brot, "Cloning the expression of a mammalian gene involved in the reduction of methionine sulfoxide residues in proteins", Proc. Natl. Acad. Sci. 93, 2095 (1996). doi: 10.1073/ pnas.93.5.2095

56. R.L. Levine, L. Mosoni, B.S. Berlett and E.R. Stadtman, "Methionine residues as endogenous antioxidants in proteins", Proc. Natl. Acad. Sci. 93, 15036 (1996). doi: $10.1073 /$ pnas.93.26.15036

57. H. Liu, G. Gaza-Bulseco and L. Zhou, "Mass spectrometry analysis of photo-induced methionine oxidation of a recombinant human monoclonal antibody", J. Am. Soc. Mass Spectrom., in press (2008).

58. M.M. Cordero, J.J. Houser and C. Wesdemiotis, "The neutral products formed during backbone fragmentations of protonated peptides in tandem mass spectrometry", Anal. Chem. 65, 1594 (1993). doi: $10.1021 /$ $\underline{\text { ac00059a019 }}$
59. B. Paisz and S. Suhai, "Combined quantum chemical and RRKM modeling of the main fragmentation pathways of protonated GGG. I. Cis-trans isomerization around protonated amide bonds", Rapid Commun. Mass Spectrom. 15, 2307 (2001). doi: 10.1002/rcm.507

60. B. Paisz and S. Suhai, "Combined quantum chemical and RRKM modeling of the main fragmentation pathways of protonated GGG. II. Formation of b2, y1, and y2 ions", Rapid Commun. Mass Spectrom. 16, 375 (2002). doi: $10.1002 / \mathrm{rcm} .586$

61. B. Paisz, S. Suhai and A.G. Harrison, "Experimental and theoretical investigation of the main fragmentation pathways of protonated H-Gly-Gly-Sar-OH and H-Gly-SarSar-OH, J. Am. Soc. Mass Spectrom. 14, 1454 (2003). doi: 10.1016/j.jasms.2003.07.001

62. B. Paisz and S. Suhai, "Towards understanding the tandem mass spectra of protonated oligopeptides. 1: mechanism of amide bond cleavage", J. Am. Soc. Mass Spectrom. 15, 103 (2004). doi: 10.1016/j. jasms.2003.09.010

63. L.L. Smith, K.A. Herrmann and V.H. Wysocki, "Investigation of gas phase ion structure for prolinecontaining $b_{2}$ ion", J. Am. Soc. Mass Spectrom. 17, 20 (2006). doi: 10.1016/j.jasms.2005.06.016

64. J. Laskin, T.H. Bailey and J.H. Futrell, "Mechanisms of peptide fragmentation from time- and energy-resolved surface-induced dissociation studies: Dissociation of angiotensin analogs", Int. J. Mass Spectrom. 249/250, 462 (2007). doi: 10.1016/j.ijms.2005.11.007

65. V. Ramesh, P. Nagi Reddy, R. Srinivas, G. Srinivasulu and A.C. Kunwar, "Differentiation of three pairs of positional isomers of hybrid peptides with repeats of phenylalanine- $\beta^{3}$-h-valine $/ \beta^{3}$-h-valine-phenylalanine by electrospray ionization tandem mass spectrometry", Rapid Commun. Mass Spectrom. 21, 1401 (2007). doi: $\underline{10.1002 /}$ rcm.2975

66. B. Balta, V. Avyente and C. Lifshitz, "Elimination of water from the carboxyl group of GlyGlyH", J. Am. Soc. Mass Spectrom. 14, 1192 (2003). doi: 10.1016/S10440305(03)00479-3

67. C. Hansch and A. Leo, Substituent Constants for Correlations Analysis in Chemistry and Biology. Wiley Interscience, New York, USA, p. 527 (1979).

68. R.A. Jockusch, P.D. Schnier, W.D. Price, E.F. Strittmatter, P.A. Demirev and E.R. Williams, "Effects of charge state on fragmentation pathways, dynamics, and activation energies of ubiquitin ions measured by blackbody infrared radiative dissociation", Anal. Chem. 69, 1119 (1997). doi: $10.1021 /$ ac960804q

69. Q. Zhang, V.H. Wysocki, P.Y. Scaraffia and M.A. Wells, "Fragmentation pathway for glutamine identification: loss of 73 Da from dimethylformamidine glutamine isobutyl ester", J. Am. Soc. Mass Spectrom. 16, 1192 (2005). doi: 10.1016/j.jasms.2005.03.052

70. H. Li and G. Yuan, "Electrospray ionization mass spectral characteristics and fragmentation mechanisms of 
angiotensin II and its analogues", Int. J. Mass Spectrom. 252, 54 (2006). doi: $\underline{\text { 10.1016/j.ijms.2006.02.016 }}$

71. Z.T. Zhu, Y.M. Li, Y.T. Guo, M. Sun and Y.F. Zhao, “Preliminary ESI-MS and MALDI-TOF analysis on phosphoryllated tetrapeptides with Xaa-Pro motif", Phosphorus Sulfur 182, 825 (2007). doi: $10.1080 / 10426500601059482$

72. C. Santos, M.L. Mateus, A.P. dos Santos, R. Moreira, E. de Oliveira and P. Gomes, "Cyclization-activated prodrugs. Synthesis, reactivity and toxicity of dipeptide esters of paracetamol", Bioorg. Med. Chem. Lett. 15, 1595 (2005). doi: 10.1016/j.bmcl.2005.01.065

73. H. Bundgaard and M. Johansen, "Prodrugs as drug delivery systems IV: N-Mannich bases as potential novel prodrug for amides, ureides, amines, and other $\mathrm{NH}$-acidic compounds", J. Pharm. Sci. 69, 44 (1980). doi: 10.1002/jps.2600690112

74. G.J. Rasmussen and H. Bundgaard, "Prodrug of peptides. 10. Protection of di- and tripeptides against aminopeptidase by formation of bioreversible 4-imidazolidinone derivatives", Int. J. Pharm. 71, 45 (1991). doi: 10.1016/0378-5173(91)90066-W

75. G.J. Rasmussen and H. Bundgaard, "Prodrug of peptides. 11. Imidazolidinone prodrug derivatives of enkephalins to prevent aminopeptidase-catalyzed metabolism in plasma and absorptive mucosae", Int. J. Pharm. 76, 113 (1991). doi: 10.1016/0378$\underline{5173(91) 90349-S}$ 